\title{
Removal of heavy metal from industrial wastewater using chitosan coated oil palm shell charcoal
}

\author{
Saifuddin M. Nomanbhay* \\ Chemistry Unit, Department of Engineering Sciences \\ College of Engineering \\ Universiti of Tenaga Nasional \\ 43900 Kajang Selangor, Malaysia \\ Tel: 60389287285 \\ Fax: 60389212116 \\ E-mail: saifuddin@uniten.edu.my \\ Kumaran Palanisamy \\ Mechanical Engineering Department \\ College of Engineering \\ Universiti of Tenaga Nasional \\ 43900 Kajang Selangor, Malaysia \\ Tel: 60389282296 \\ Fax: 60389212116 \\ E-mail: kumaran@uniten.edu.my
}

Financial support: Uniten Research Seed Fund - J 510010215.

Keywords: chitosan bioabsorbent, chromium (III), chromium (IV), heavy metal adsorption, oil palm shell charcoal.

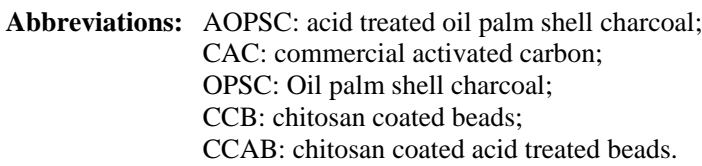

Abbreviations: AOPSC: acid treated oil palm shell charcoal;

CAC: commercial activated carbon;

OPSC: Oil palm shell charcoal;

CCB: chitosan coated beads;

CCAB: chitosan coated acid treated beads.

This research focuses on understanding biosorption process and developing a cost effective technology for treatment of heavy metals-contaminated industrial wastewater. A new composite biosorbent has been prepared by coating chitosan onto acid treated oil palm shell charcoal (AOPSC). Chitosan loading on the AOPSC support is about $21 \%$ by weight. The shape of the adsorbent is nearly spherical with particle diameter ranging 100 150 $\mu \mathrm{m}$. The adsorption capacity of the composite biosorbent was evaluated by measuring the extent of adsorption of chromium metal ions from water under equilibrium conditions at $25^{\circ} \mathrm{C}$. Using Langmuir isotherm model, the equilibrium data yielded the following ultimate capacity values for the coated biosorbent on a per gram basis of chitosan: $154 \mathrm{mg}$ $\mathrm{Cr} / \mathrm{g}$. Bioconversion of $\mathrm{Cr}$ (VI) to $\mathrm{Cr}$ (III) by chitosan was also observed and had been shown previously in other studies using plant tissues and mineral surfaces. After the biosorbent was saturated with the metal ions, the adsorbent was regenerated with $0.1 \mathrm{M}$ sodium hydroxide. Maximum desorption of the metal takes place within 5 bed volumes while complete desorption occurs within 10 bed volumes. Details of preparation of the biosorbent, characterization, and adsorption studies are presented. Dominant sorption mechanisms are ionic interactions and complexation.

At least 20 metals are classified as toxic and half of these are emitted into the environment in quantities that pose risks to human health (Kortenkamp et. al. 1996). Chromium has both beneficial and detrimental properties. Two stable oxidation states of chromium persist in the environment, $\mathrm{Cr}$ (III) and $\mathrm{Cr}$ (VI), which have contrasting toxicities, mobilities and bioavailabilities. Whereas $\mathrm{Cr}$ (III) is essential in human nutrition (especially in glucose metabolism), most of the hexavalent compounds are toxic, several can even cause lung cancer. While $\mathrm{Cr}$ (III) is relatively innocuous and immobile, $\mathrm{Cr}$ (VI) moves readily through soils and aquatic environments and is a strong oxidizing agent capable of being absorbed through the skin (Park and Jung, 2001). Chromium and its compounds are widely used in electroplating, leather tanning, cement, dyeing, metal processing, wood preservatives, paint and pigments, textile, steel fabrication and canning industries These industries produce large quantities of toxic

\footnotetext{
Corresponding author
} 
wastewater effluents (Raji and Anirudhan, 1997). The maximum concentration limit for $\mathrm{Cr}$ (VI) for discharge into inland surface waters is $0.1 \mathrm{mg} / \mathrm{l}$ and in potable water is $0.05 \mathrm{mg} / \mathrm{l}$ (EPA, 1990).

A wide range of physical and chemical processes is available for the removal of $\mathrm{Cr}$ (VI) from wastewater, such as electro-chemical precipitation, ultrafiltration, ion exchange and reverse osmosis (Rengaraj et al. 2001; Yurlova et al. 2002; Benito and Ruiz, 2002). A major drawback with precipitation is sludge production. Ion exchange is considered a better alternative technique for such a purpose. However, it is not economically appealing because of high operational cost. Adsorption using commercial activated carbon (CAC) can remove heavy metals from wastewater, such as Cd (Ramos et al. 1997); Ni (Shim et al. 2001); Cr (Ouki et al. 1997); Cu (Monser and Adhoum, 2002). However, CAC remains an expensive material for heavy metal removal.

Natural biopolymers are industrially attractive because of their capability of lowering transition metal-ion concentration to parts per billion concentrations. Natural materials that are available in large quantities or certain waste from agricultural operations may have potential to be used as low cost adsorbents, as they represent unused resources, widely available and are environmentally friendly (Deans and Dixon, 1992). In Malaysia, oil palm is the most important commercial crop. The explosive expansion of oil palm plantation has generated enormous amounts of vegetable waste. It was reported that Malaysia currently produces about 30 million tonnes annually of oil palm biomass, including trunks, fronds, fruit waste and empty fruit brunches. Of these, about two million tonnes of fruit shell (or endocarp) is generated annually (Chan, 1999). Preliminary studies have shown that it is feasible to prepare chars with sufficient densities and high porosity from oil palm fruit waste (Guo and Lua, 1998). The exchange/sorption properties of palm oil shell are due to the presence of some functional groups, such as carboxylic, hydroxyl, and lactone, which have a high affinity for metal ions (Tan et al. 1993). In recent years, development of surface modified activated carbon has generated a diversity of activated carbon with far superior adsorption capacity. The use of palm oil shell with surface modification to improve its metal removal performance would add its economic value, help reduce the cost of waste disposal, and most importantly, provide a potentially inexpensive alternative to existing commercial activated carbon.

Among the many other low cost absorbents identified (Olin et al. 1996; Bailey et al. 1999, Bailey et al. 1997) chitosan has the highest sorption capacity for several metal ions (Deshpande, 1986). Chitin (2-acetamido-2-deoxy- $\beta$-Dglucose-(N-acetylglucan) is the main structural component of molluscs, insects, crustaceans, fungi, algae and marine invertebrates like crabs and shrimps (Deshpande, 1986; Chen and Chang, 1994; Ilyina et al. 1995). Worldwide, the solid waste from processing of shellfish, crabs, shrimps and krill constitutes large amount of chitinaceous waste. Chitosan (2-acetamido-2-deoxy- $\beta$-D-glucose-(Nacetylglucosamine) is a partially deacetylated polymer of chitin and is usually prepared from chitin by deacetylation with a strong alkaline solution as shown in Figure 1.

Chitosan chelates five to six times greater amounts of metals than chitin. This is attributed to the free amino groups exposed in chitosan because of deacetylation of chitin (Yang and Zall, 1984). The biosorbent material, chitosan, is slightly soluble at low pHs and poses problems for developing commercial applications. It is also soft and has a tendency to agglomerate or form a gel in aqueous solutions. In addition, the active binding sites of chitosan are not readily available for sorption. Transport of the metal contaminants to the binding sites plays a very important role in process design. Therefore, it is necessary to provide physical support and increase the accessibility of the metal binding sites for process applications.

In the present investigation an attempt was made to overcome these mass transfer limitations by synthesizing a biosorbent by coating chitosan on the surface of palm oil shell charcoal and evaluating its equilibrium adsorption

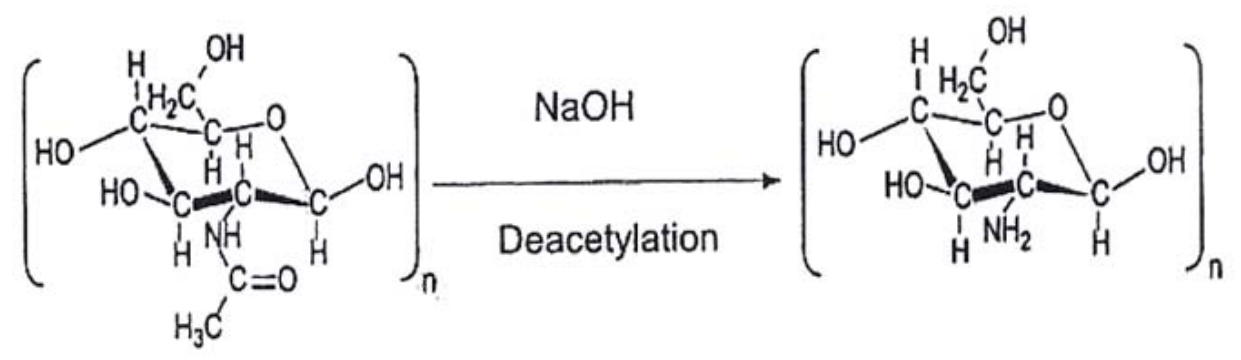

Chitin

2-acetamido-2-deoxy- $\beta$ - $\mathrm{D}$-glucose-( $\mathrm{N}$-acetylglucan)
Chitosan

2-acetamido-2-deoxy- $\beta$-D-glucose-( $\mathrm{N}$-acetylglucosamine)

Figure 1. Conversion of chitin to chitosan by deacetylation. 
Table 1. Characteristics of oil palm shell and derived char (Guo and Lua, 2000).

\begin{tabular}{|c|c|c|c|}
\hline & $\begin{array}{c}\text { Solid density } \\
\mathbf{r}_{\mathrm{s}}\left(\mathbf{g} / \mathrm{cm}^{3}\right)\end{array}$ & $\begin{array}{c}\text { Apparent density, } \\
\mathbf{r}_{\mathbf{a}}\left(\mathbf{g} / \mathbf{c m}^{3}\right)\end{array}$ & $\begin{array}{c}\text { Porosity, } \\
\left.\mathbf{e}\left[\mathrm{r}_{\mathrm{s}}-\mathrm{r}_{\mathrm{a}}\right] / \mathbf{r}_{\mathrm{s}}\right] \mathbf{x} 100 \%\end{array}$ \\
\hline Oil palm shell & 1.53 & 1.47 & 3.9 \\
\hline Shell char & 1.62 & 1.31 & 19.1 \\
\hline
\end{tabular}

properties. The combination of the useful properties of oil palm shell char and that of natural chitosan, could introduce a composite matrix with many application and superior adsorption capabilities. Using synthetic wastewater, the $\mathrm{Cr}$ removal by oil palm shell charcoal coated with chitosan and acid treated oil palm shell charcoal adsorbents were statically compared.

\section{MATERIALS AND METHODS}

\section{Char preparation from oil palm shell}

Oil palm shell was obtained from MPOB Bangi, Selangor, Malaysia. Preparation of char from the oil palm shell was carried as previously described (Guo and Lua, 2000). Oil palm shell is a suitable raw material for making high quality activated carbon because of their inherent high densities and carbon contents, especially after pyrolysis (Gua and Lua, 2000). As received oil palm shell was first dried at $110^{\circ} \mathrm{C}$ for 24 hrs to reduce the moisture content. The dried shell was cut, ground and sieved. Size fractions of 2.0-2.8 mm were used. Pyrolysis was carried out in a horizontal controlled atmosphere furnace (Carbolite, CTE 12/75). About $15 \mathrm{~g}$ of the sample was placed in an alumina boat, and pushed into the hot zone of the furnace. During pyrolysis, nitrogen at a flow rate of $150 \mathrm{~cm}^{3} / \mathrm{min}$ was used as purge gas. The furnace temperature was increased at a rate of $10^{\circ} \mathrm{C} / \mathrm{min}$ from room temperature to $600^{\circ} \mathrm{C}$ and was held at this temperature for 2 hrs. The weight lost was obtained from the weight before and after pyrolysis. The pyrolysed sample was crushed into powder form.

\section{Preparation of chitosan}

Chitin (from crab shells) was purchased from Sigma Chemical Co., St. Louis, MO. Pectinex Ultra SP-L (a highly purified preparation of pectolytic enzymes from a selected strain of Aspergillus niger) was from Novo Nordisk, Denmark. Cabbage was obtained from the local market. All other chemicals used were of analytical grade.

The deacetylation method of Coughlin et al. 1990, was used with slight modification. The commercially obtained chitin was first ground in a blender and sieved. Particles in the size range $0.5-1.0 \mathrm{~mm}$ were first soaked in a $5 \%$ hydrochloric acid solution for $1 \mathrm{hr}$ at room temperature to remove calcium salts (demineralization). After rinsing with distilled water, the decalcified chitin was transferred to a $50 \%$ sodium hydroxide solution. The solution was irradiated in a domestic microwave oven (EME2662, Electrolux, operating frequency $2.5 \mathrm{GHz}$ ) for $10 \mathrm{~min}$ (power level $150 \mathrm{~W}$ ) for deacetylation. After rinsing with distilled water and drying at $60^{\circ} \mathrm{C}$, the deacetylated chitin (now known as chitosan) was ready for use.

\section{Preparation of chitosan gel}

About $50 \mathrm{~g}$ of chitosan was slowly added to $1000 \mathrm{ml}$ of 10 wt\% oxalic acid with constant stirring. The mixture was also heated to $40-50^{\circ} \mathrm{C}$ to facilitate mixing. At room temperature, the chitosan-oxalic acid mixture formed a whitish viscous gel.

\section{Oxidizing OPSC with sulfuric acid}

For conditioning, the previously described method of Kadirvelu et al. 2001, was used. OPSC was washed with deionized water until any leachable impurities due to free acid and adherent powder were removed. The samples were then treated with $2 \% \mathrm{H}_{2} \mathrm{SO}_{4}(\mathrm{v} / \mathrm{v})$ in an incubator at $110^{\circ} \mathrm{C}$ for 24 hrs and soaked with deionized water until the solution $\mathrm{pH}$ was stable. Then, the adsorbent was soaked in $2 \% \mathrm{NaHCO}_{3}(\mathrm{w} / \mathrm{v})$ till any residual acid left was removed. Finally, the samples (hereafter called acid treated oil palm shell char -AOPSC) were dried overnight in an oven at $110^{\circ} \mathrm{C}$, cooled at room temperature, and stored in a desiccator until use (Kadirvelu et al. 2001).

\section{Surface coating of AOPSC and OPSC with chitosan}

About $500 \mathrm{ml}$, of the chitosan gel was diluted with water $(\sim 500 \mathrm{ml})$ and heated to $40-50^{\circ} \mathrm{C}$. About $500 \mathrm{~g}$ of the AOPSC (from section 2.4 above) was slowly added to the diluted gel and mechanically agitated using a rotary shaker at $150 \mathrm{rpm}$ for $24 \mathrm{hrs}$. The gel coated AOPSC was then washed with deionized water and dried. The process was repeated for three times to form a thick coating of chitosan on the AOPSC surface. The amount of chitosan coated was determined to be about $26 \%$ by weight. The chitosan coated 


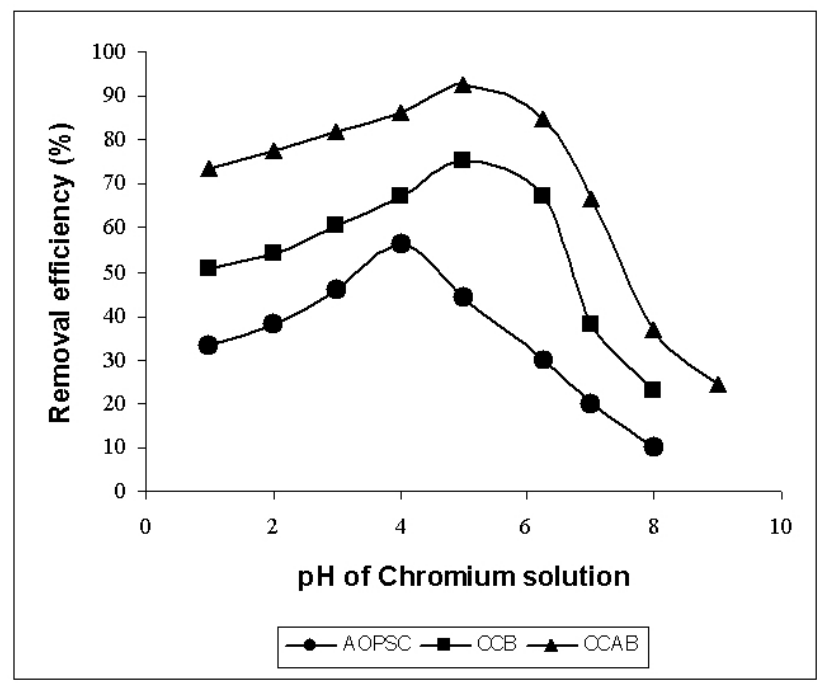

Figure 2. Effect of $\mathrm{pH}$ on the adsorption of Chromium ions on various adsorbents.

$\mathrm{Cr}(\mathrm{VI})$ concentration was $20 \mathrm{mg} / \mathrm{ml}$;

Agitation speed: 200 rpm.;

Contact time: 3 hrs;

Amount of each adsorbent: $40 \mathrm{~g} /$;

Temperature was maintained at $25^{\circ} \mathrm{C}$.

AOPSC (now called chitosan coated acid treated beads, $\mathrm{CCAB}$ ) were removed and neutralized by putting them in $0.5 \% \mathrm{NaOH}$ solution for 3 hrs. The CCAB were then extensively rinsed with deionized water and dried (Babel and Kurniawan, 2004). Similarly OPSC were also coated with chitosan as described above. The chitosan coated OPSC were called chitosan coated beads (CCB).

\section{Determination of pHpzc}

The determination of the pHpzc of the samples was carried out as described previously (Rivera et al. 2001): $50 \mathrm{~cm}^{3}$ of $0.01 \mathrm{M} \mathrm{NaCl}$ solution was placed in a closed Erlenmeyer flask. The $\mathrm{pH}$ was adjusted to a value between 2 and 12 by adding $\mathrm{HCl} 0.1 \mathrm{M}$ or $\mathrm{NaOH} 0.1 \mathrm{M}$ solutions. Then, $0.15 \mathrm{~g}$ of OPSC sample was added and the final $\mathrm{pH}$ measured after 48 hrs under agitation at room temperature. The $\mathrm{pH}_{\mathrm{pzc}}$ is the point where the curve $\mathrm{pH}_{\text {final }}$ vs. $\mathrm{pH}_{\text {initial }}$ crosses the line $\mathrm{pH}_{\text {initial }}=\mathrm{pH}_{\text {final }}$. Similarly, the $\mathrm{pH}_{\mathrm{pzc}}$ was also determined for CCAB and CCB samples using the above method.

\section{Equilibrium uptake experiments}

Batch equilibrium experiments were carried out using CCB, CCAB as well as AOPSC as adsorbents. Potassium dichromate $\left(\mathrm{K}_{2} \mathrm{Cr}_{2} \mathrm{O}_{7}\right)$ (Fluka, Switzerland) was used as the source of $\mathrm{Cr}(\mathrm{VI})$ in the synthetic wastewater. The $\mathrm{Cr}$ stock solution (500 mg/l) was prepared by dissolving $0.707 \mathrm{~g}$ of $\mathrm{K}_{2} \mathrm{Cr}_{2} \mathrm{O}_{7}$ in $500 \mathrm{ml}$ of deionized water. A series of flasks containing dichromate solutions of varying concentrations from 5 to $25 \mathrm{mg} / \mathrm{l}$ prepared from the stock solution. Adjustment of $\mathrm{pH}$ was carried out using $0.1 \mathrm{~N} \mathrm{NaOH}$ and/or $0.1 \mathrm{~N} \mathrm{H}_{2} \mathrm{SO}_{4}$. Agitation of the system under investigation was carried out on a rotary shaker (Daiki Science Co. Ltd. South Korea).

To maximize $\mathrm{Cr}$ removal by the adsorbent, batch experiments were conducted at ambient temperature using the optimum conditions of all pertinent factors, such as dose, $\mathrm{pH}$, agitation speed, and contact time (Chakravarty et al. 2002). Subsequent adsorption experiments were carried out with only optimized parameters. Adsorption isotherm tests were also carried out in the reaction mixture consisting of $1.5 \mathrm{~g} / \mathrm{l}$ of adsorbent and $100 \mathrm{ml}$ of $\mathrm{Cr}$ solution with varying chromium concentration from 5 to $25 \mathrm{mg} / \mathrm{l}$. The change in $\mathrm{Cr}$ (VI) concentration due to adsorption was determined colorimetrically (Shimadzu spectrophotometer) according to Standard Methods (Clesceri et al. 1998). A purple-violet coloured complex was developed in the reaction between $\mathrm{Cr}$ (VI) and 1,5diphenylcarbazide in acidic condition. Absorbance was measured at wavelength $(\lambda) 540 \mathrm{~nm}$.

The removal efficiency $(E)$ of adsorbent on $\mathrm{Cr}(\mathrm{VI})$ was defined as

$$
E(\%)=\left[\left(\mathrm{C}_{0}-\mathrm{C}_{1}\right) / \mathrm{C}_{0}\right] \times 100
$$

where $\mathrm{C}_{0}$ and $\mathrm{C}_{1}$ are the initial and equilibrium concentration of $\mathrm{Cr}$ solution (mg/ l), respectively.

To ensure the accuracy, reliability, and reproducibility of the collected data, all the batch experiments were carried out in duplicate and the mean values of two data sets are presented. When the relative error exceeded the relative standard deviation by more than $1.0 \%$, the data were disregarded and a third experiment was conducted until the relative error fell within an acceptable range.

\section{RESULTS AND DISCUSSION}

\section{Oil palm shell char}

Oil palm shell has been successfully used to produce high quality activated carbon because of their inherent high densities and carbon content (Normah et al. 1995; Hussein et al. 1996; Guo and Lua, 2000). In this work char from oil palm shell was prepared according to the method described by Guo and Lua, 2000. No attempt was made to determine the solid density and apparent densities of both the starting material and the char. Table 1, gives the solid and apparent densities and porosities of both the shell and its char as reported by Guo and Lua, 2000.

\section{Preparation of chitosan}

Many of the methods reported for converting chitin in crustacean shell to chitosan are slow and consume significant amounts of reagents. A relatively rapid and mild 
Table 2. Isotherm model constants and correlation coefficients for adsorption of chromium ions from aqueous solution using various adsorbents.

\begin{tabular}{|l|c|c|c|c|c|c|}
\hline \multicolumn{1}{|c|}{ Type of adsorbent } & \multicolumn{3}{c|}{ Langmuir } & \multicolumn{3}{c|}{ Freundlich } \\
\hline & $\frac{a_{L}}{K_{L}}(\mathrm{mg} / \mathrm{g})$ & $\mathrm{K}_{\mathrm{L}}(\mathrm{mol} / \mathrm{L})$ & $\mathrm{R}^{2}$ & $a$ & $b$ & $\mathrm{R}^{2}$ \\
\hline Chitosan coated acid treated oil palm shell charcoal (CCAB) & 60.25 & 2954 & 0.997 & 10.67 & 0.594 & 0.973 \\
\hline Chitosan coated oil palm shell charcoal (CCB) & 52.68 & 2004 & 0.996 & 9.59 & 0.489 & 0.956 \\
\hline Acid treated oil palm shell Charcoal (AOPSC) & 44.68 & 1766 & 0.996 & 7.36 & 0.389 & 0.951 \\
\hline
\end{tabular}

deacetylation method proposed by Coughlin et al. 1990 with slight modification where the deacetylation process was subjected to microwave irradiation was used in this work. During microwave irradiation, polar molecules such as water (in the sample) align with the continuously changing magnetic field generated by microwaves. This is supposed to accelerate various chemical, biological, and physical processes (Caddick, 1995; Sridar, 1998; Khmelnitsky and Rich, 1999). Microwave treatment brings about greater accessibility of the susceptible bonds and hence a much more efficient chemical reaction (Roy et al. 2003).

The practical problems of chitosan solubility at low $\mathrm{pH}$ aqueous systems, gel forming behaviour and mass transfer limitations were overcome by coating it on other adsorbents like alumina, charcoal or interacting it with other adsorbents like alginate to form a rigid matrix structure of better mechanical strength (Babel and Kurniawan, 2004; Gotoh et al. 2004). In this study these problems were overcome by coating chitosan on oil palm shell charcoal and the coating process yielded a stable granular composite adsorbent that was stable under acidic conditions. The cationic nature of chitosan and the anionic nature of oil palm shell charcoal yielded stable, granular composite matrix due to interaction between the two oppositely charged materials. Chitosan binds with both anionic and cationic species. Chromium (VI) and some other metals such as arsenic, depending on the $\mathrm{pH}$, are known to exist as anions. Chromium (VI) forms dichromate anion at $\mathrm{pH}$ around 4. The amine groups of chitosan are largely responsible for the absorption of $\mathrm{Cr}$ (VI) ions from the solution (Fu et al. 1997; Dambies et al. 2001). At low pH, the amine group on chitosan is protonated. This leads to the interaction between $\mathrm{NH}_{3}{ }^{+}$functional groups in chitosan and $\mathrm{Cr}_{2} \mathrm{O}_{7}{ }^{2-}$ and the interaction is chiefly electrostatic attraction in nature (Fu et al. 1997).

\section{Factors influencing the adsorption of $\mathrm{Cr}(\mathrm{VI})$ ions}

The influence of several operational parameters such as dose of adsorbent, agitation speed, initial $\mathrm{pH}$ and contact time was investigated. The result were expressed as the removal efficiency $(E)$ of the adsorbent on $\mathrm{Cr}$, which was defined as

$$
E(\%)=\left[\left(\mathrm{C}_{0}-\mathrm{C}_{1}\right) / \mathrm{C}_{0}\right] \times 100 \text {, where }
$$

$\mathrm{C}_{\mathrm{o}}$ and $\mathrm{C}_{1}$ are the initial and equilibrium concentration of $\mathrm{Cr}$ solution (mg/l), respectively. The $\mathrm{Cr}$ (VI) ion concentration was determined colourimetrically according to Standard Methods (Clesceri et al. 1998).

Effect of pH. pH is an important parameter for adsorption of metal ions from aqueous solution because it affects the solubility of the metal ions, concentration of the counter ions on the functional groups of the adsorbent and the degree of ionization of the of the adsorbate during reaction. To examine the effect of $\mathrm{pH}$ on the $\mathrm{Cr}$ removal efficiency, the $\mathrm{pH}$ was varied from 1.0 to 9.0. As shown in Figure 2 the uptake of free ionic $\mathrm{Cr}$ depends on $\mathrm{pH}$, where optimal metal removal efficiency occurs at $\mathrm{pH} 5$ and then declining at higher $\mathrm{pH}$. Removal efficiency for CCAB increased from $65 \%$ to $92 \%$ over $\mathrm{pH}$ range from 1.0 to 5.0 . The other two adsorbents, i.e. chitosan coated oil palm shell carbon and acid treated oil palm shell charcoal also showed similar trends but with much lower removal efficiency and slight different optimum $\mathrm{pH}$ value. Chromium (VI) and some other metals such as arsenic, depending on the $\mathrm{pH}$, are known to exist as anions. At low $\mathrm{pH}$ (below 4), the amine group on chitosan is protonated to varying degree. The $\mathrm{pH}_{\mathrm{pzc}}$ obtained for both CCAB and CCB was in the range of 6.8 - 7.1. This is consistent with results reported for chitosan from lobster and crab which is in the range of 6.47.2 (Dambies et al. 2001). The $\mathrm{pH}_{\mathrm{pzc}}$ is a point at which the surface acidic (or basic) functional groups no longer contribute to the $\mathrm{pH}$ value of the solution. The $\mathrm{pH}_{\mathrm{pzc}}$ value of acid treated OPSC was found to be around 4.7. It can be concluded that oxidization of oil palm shell charcoal with sulphuric acid yielded acidic surface since $\mathrm{pH}$ values of point of zero charge for these materials are at a lower $\mathrm{pH}$ range compared to the value reported for most chemically 
untreated commercial activated carbon (Menendez et al. 1996). The surface acidity was due to the introduction of several oxygen-containing functional groups (Faria et al. 2004). Cations adsorption will be favourable at $\mathrm{pH}$ value higher than $\mathrm{pH}_{\mathrm{ZPC}}$, and anions adsorption at $\mathrm{pH}$ values lower than $\mathrm{pH}_{\mathrm{ZPC}}$. The $\mathrm{NH}_{3}{ }^{+}$group on the chitosan is chiefly responsible for $\mathrm{Cr}$ (VI) adsorption. Chromium (VI) forms stable anions, such as $\mathrm{Cr}_{2} \mathrm{O}_{7}{ }^{2-}, \mathrm{HCrO}_{4}{ }^{-}, \mathrm{CrO}_{4}{ }^{2-}$, and $\mathrm{HCr}_{2} \mathrm{O}_{7}^{-}$, the fraction of any particular species is dependent upon the chromium concentration and $\mathrm{pH}$ (Udaybhaskar et al. 1990). From the $\mathrm{pK}_{\mathrm{a}}$ value of chitosan, it can be calculated that the extent of protonation is $9,50,91$, and $99 \%$ at $\mathrm{pH}$ 7.3, 6.3, 5.3, and 4.3, respectively (Dambies et al. 2001). This leads to the interaction between $\mathrm{NH}_{3}{ }^{+}$ functional groups and the chromate anions. With increase in $\mathrm{pH}$ from 5 to 9, the degree of protonation of the adsorbent functional group decreased gradually and hence removal was decreased. Above the $\mathrm{pK}_{\mathrm{a}}$ value the chitosan adsorbent will be negatively charged. X-ray photoelectron spectroscopy spectrum by Tiemann et al. (1999) and Dambies et al. (2001) of chitosan biomass after contact with chromium (VI) at pH around 5, reveals that about 55\% of chromium (VI) gets reduced to chromium (III). Similar bioreduction process can also be accomplished using alfalfa, seaweed, and some lyophilized plant tissue (Wittbrodt and Palmer, 1996; Lytle et al. 1998). The positively charged $\mathrm{Cr}$ (III) ions can bind by way of electrostatic interaction with the negatively charged surface of chitosan, mainly through carboxyl ligands.

The oxidative treatment of OPSC with sulphuric acid will introduce more acidic $\mathrm{C}=\mathrm{O}$ groups on the surface of OPSC (Mostafa, 1997; Toles et al. 1999). This enhanced the electrostatic interaction between chitosan and the more negatively charged AOPSC and this prevents any tendency of chitosan to agglomerate. This helped to increase the availability of active binding sites on the chitosan for adsorption of $\mathrm{Cr} \mathrm{VI}$ at low $\mathrm{pH}$ conditions. It has also been suggested that formation of more acidic surface oxides on the carbon surface enhances its hydrophilic character and hence improve the hydrodynamic flow (Olin et al. 1996). On the other hand, chitosan coated beads, showed lower adsorption capacity, probably due to less efficient coating of chitosan on OPSC, which has lesser acidic surface oxides. The interaction may not be very strong and the chitosan may agglomerate to a certain degree and become more soluble at low $\mathrm{pH}$ and hence reduces the availability of active binding sites on the chitosan for adsorption of $\mathrm{Cr}$ (VI). Activated carbons are species with amphoteric character, thus depending on the $\mathrm{pH}$ of the solution their surfaces might be positively charged or negatively charged. Adsorption of anionic species will be favoured at $\mathrm{pH}$ lower than $\mathrm{pH}_{\mathrm{pzc}}$ and vice versa for cationic species (RodriguesReinoso, 1998). The AOPSC used as comparison showed the lowest removal efficiency. The optimum $\mathrm{pH}$ was around 4.0. The removal efficiency reduced drastically from $\mathrm{pH} 4$ to 8 . At higher $\mathrm{pH}$, the presence of oxygencontaining functional groups, makes the adsorbent surface negatively charged and hence there is repulsive electrostatic interaction between the adsorbent and the anions (Radovic et al. 1997; Faria et al. 2004). At pH greater than 8.5, insoluble chromium hydroxide starts precipitating from the solution, making true sorption studies impossible.

Influence of dose. The dependence of $\mathrm{Cr}$ sorption on dose was studied by varying the amount of adsorbents from 1.5 to $30 \mathrm{~g} / \mathrm{l}$, while keeping other parameters $(\mathrm{pH}$, agitation speed, and contact time) constant. Figure 3 presents the $\mathrm{Cr}$ removal efficiency for all the three types of adsorbents used. Form the Figure 3, it can be observed that removal efficiency of the adsorbent generally improved with increasing dose. This is expected due to the fact that the higher dose of adsorbents in the solution, the greater availability of exchangeable sites for the ions. All of them showed no further increase in adsorption after a certain amount of adsorbent was added (13-30 g/l). At $20 \mathrm{mg} / \mathrm{l}$ concentration of $\mathrm{Cr}$ (VI), the maximum $\mathrm{Cr}$ (VI) removal efficiency was about $86 \%$ for a CCAB at the dosage of 13.5 $\mathrm{g} / \mathrm{l}$, while for CCB it was $64 \%$ at the dosage of $18 \mathrm{~g} / \mathrm{l}$ and commercial activated carbon was $52 \%$ at dosage of $24 \mathrm{~g} / \mathrm{l}$. This suggests that after a certain dose of adsorbent, the maximum adsorption sets in and hence the amount of ions bound to the adsorbent and the amount of free ions remains constant even with further addition of the dose of adsorbent.

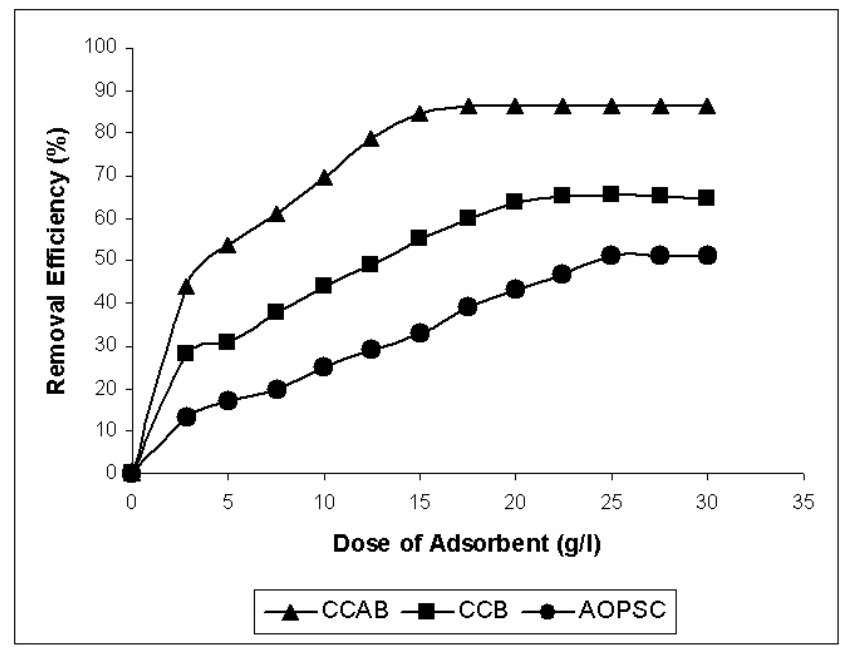

Figure 3. Effect of dose on the equilibrium removal efficiencies of Chromium ions using different types of adsorbents. $\mathrm{Cr}(\mathrm{Vl})$ concentration was $20 \mathrm{mg} / \mathrm{ml}$;

Agitation speed : 200 rpm;

Contact time: $3 \mathrm{hrs;}$

$\mathrm{pH}$ of solution: 4 ;

Temperature was maintained at $25^{\circ} \mathrm{C}$.

It is interesting to note that the saturated values of $\mathrm{Cr}$ (VI) removal efficiency of the three types of adsorbents are 
different from one to another due to the extent of surface modification. Chromium (VI) and some other metals such as arsenic, depending on the $\mathrm{pH}$, are known to exist as anions. At low $\mathrm{pH}$ (below 5), the amine group on chitosan is protonated to varying degree (Mostafa, 1997; Toles et al. 1999). The $\mathrm{NH}_{3}{ }^{+}$group on the chitosan is chiefly responsible for interaction with anions and negatively charged surfaces. It has also been suggested that the oxidative treatment of OPSC with sulphuric acid would introduce more acidic $\mathrm{C}=\mathrm{O}$ groups on the surface of OPSC (Mostafa, 1997; Toles et al. 1999). This would enhance the electrostatic interaction between chitosan and the more negatively charged AOPSC and this prevents any tendency of chitosan to agglomerate. It has also been suggested that formation of more acidic surface oxides on the carbon surface enhances its hydrophilic character and hence improve the hydrodynamic flow (Olin et al. 1996). Chitosan coated beads, showed lower adsorption capacity, probably due to less efficient coating of chitosan on OPSC, which has lesser acidic surface oxides. The interaction may not be very strong and the chitosan may agglomerate to a certain degree and hence reduces the availability of active binding sites on the chitosan for adsorption of $\mathrm{Cr}(\mathrm{VI})$. AOPSC showed poorer adsorption capability for $\mathrm{Cr}(\mathrm{VI})$ as compared with the other two adsorbents. This is consistent with the previous result (section Effect of $\mathrm{pH}$ ) obtained on effect of $\mathrm{pH}$. A close relationship between the surface basicity of the adsorbents and the anions is evident.

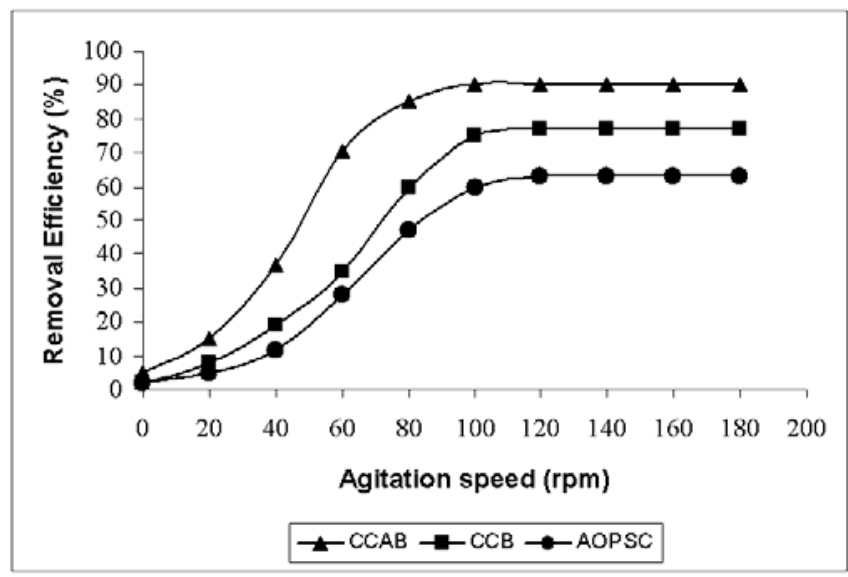

Figure 4. Effect of agitation on the equilibrium removal efficiencies of $\mathrm{Cr}(\mathrm{VI})$ using different types of adsorbents.

$\mathrm{Cr}$ (VI) concentration was $20 \mathrm{mg} / \mathrm{l}$;

Contact time: $3 \mathrm{hrs}$;

$\mathrm{pH}$ of solution was 4

Amount of each adsorbent: $40 \mathrm{~g} / \mathrm{l}$;

Temperature was maintained at $25^{\circ} \mathrm{C}$.

This is similar to the findings of others, where the interaction between oxygen-free Lewis basic sites and the free electrons of the anions, as well as the electrostatic interactions between the anions and the protonated sites of the adsorbent are the main adsorption mechanism (Leon y
Leon et al. 1992; Radovic et al. 1997; Faria et al. 2004).

Effect of agitation speed. The effect of agitation speed on removal efficiency of $\mathrm{Cr}$ was studied by varying the speed of agitation from 0 (without shaking) to $200 \mathrm{rpm}$, while keeping the optimum dose of adsorbents and optimum pH as constant. As can be seen from Figure 4, the Cr removal efficient generally increased with increasing agitation speed. The $\mathrm{Cr}$ removal efficiency of CCAB adsorbent increased from $70 \%$ to $90 \%$ when agitation speed increased from $50 \mathrm{rpm}$ to $100 \mathrm{rpm}$ and the adsorption capacity remained constant for agitation rates greater than $100 \mathrm{rpm}$. The results show significant difference using $t$ test $(\mathrm{P}=0.05)$, for all types of adsorbents, presenting standard deviation equal to 0.1 . These results can be associated to the fact that the increase of the agitation speed, improves the diffusion of $\mathrm{Cr}$ ions towards the surface of the adsorbents. This also indicates that a shaking rate in the range 100-200 rpm is sufficient to assure that all the surface binding sites are made readily available for $\mathrm{Cr}$ uptake. Then, the effect of external film diffusion on adsorption rate can be assumed not significant. For convenience, agitation speed of $150 \mathrm{rpm}$ was selected as the optimum speed for all the adsorbents.

Effect of contact time. Results (Figure 5) indicate that removal efficiency increased with an increase in contact time before equilibrium is reached. Other parameters such as dose of adsorbent, $\mathrm{pH}$ of solution and agitation speed was kept optimum, while temperature was kept at $25^{\circ} \mathrm{C}$. It can be seen that $\mathrm{Cr}$ removal efficiency of CCAB increased from $60 \%$ to $90 \%$ when contact time was increased from 30 to 180 min. Optimum contact time for both CCAB and CCB adsorbents was found to be $180 \mathrm{~min}$, compared to that of AOPSC which was 300 min. Hence the chitosan coated beads require a shorter contact time. Greater availability of various functional groups on the surface of chitosan, which are required for interaction with anions and cations, significantly improved the binding capacity and the process proceeded rapidly. This result is important, as equilibrium time is one of the important parameters for an economical wastewater treatment system.

Adsorption isotherm. To examine the relationship between sorbed $\left(q_{e}\right)$ and aqueous concentration $C_{e}$ at equilibrium, sorption isotherm models are widely employed for fitting the data, of which the Langmuir and Freundlich equations are most widely used. The Langmuir model assumes that the uptake of metal ions occurs on a homogenous surface by monolayer adsorption without any interaction between adsorbed ions. To get the equilibrium data, initial chromium concentration were varied while the adsorbent mass in each sample was kept constant. 3 hrs of equilibrium periods for sorption experiments were used to ensure equilibrium conditions. The Langmuir model takes 
the form:

$$
q_{e}=\frac{K_{L} C_{e}}{1+a_{L} C_{e}}
$$

where $q_{e}(\mathrm{mg} / \mathrm{g})$ is the amount of metal ions adsorbed onto the unit mass of the adsorbent to form a complete monolayer on the surface. $K_{L}$ is the Langmuir equilibrium constant which is related to the affinity of binding sites; $C_{e}$ the solution phase metal ion concentration, and $\alpha_{L}$ is the Langmuir constant (Aksu, 2001). The constants $K_{L}$ and $\alpha_{L}$ are the characteristics of the Langmuir equation and can be determined from a linerized form of the Langmuir equation, represented

$$
\frac{C_{e}}{q_{e}}=\frac{1}{K_{L}}+\frac{a_{L}}{K_{L}} C_{e}
$$

Therefore, a plot of $C_{e} / q_{e}$ ) versus $C_{e}$, gives a straight line of slope $\alpha_{L} / K_{L}$ and intercept $1 / K_{L}$. The constant $K_{L}$ is the Langmuir equilibrium constant and the ratio $\alpha_{L} / K_{L}$ gives the theoretical monolayer saturation capacity. On the other hand, the Freundlich equation is an empirical equation based on adsorption on a heterogeneous surface. The equation is commonly represented by

$$
q_{e}=a C_{e}^{b}
$$

where $a$ and $b$ are the Freundlich constants characteristics of the system, indicating the adsorption capacity and the adsorption intensity, respectively. To simplify the derivation of $a$ and $b$, above equation can be linearized as

$$
\ln q_{e}=b \ln C_{e}+\ln a
$$

Therefore, a plot of $\ln q_{e}$ versus $\ln C_{e}$ enables the constant $a$ and exponent $b$ to be determined. The Langmuir and Freundlich equations were used to describe the data derived from the adsorption of $\mathrm{Cr}$ by each adsorbent over the entire concentration range studied. The plot of $C_{e} / q_{e}$ ) versus $C_{e}$ showed that the experimental data reasonably well fitted the linearized equation of the Langmuir isotherm over the whole $\mathrm{Cr}$ concentration range studied. Linear plots of $\ln q_{e}$ versus $\ln C_{e}$ showed that the Freundlich isotherm was also representative for the $\mathrm{Cr}$ adsorption by all types of adsorbent tested. In this study, however, Langmuir isotherm has a better fitting model than Freundlich as the former have higher correlation regression coefficient than the latter (Table 2) thus, indicating to the applicability of a monolayer coverage of the $\mathrm{Cr}$ on the surface of adsorbent. This can be explained due to the fact that activated charcoal has a small surface area for metal adsorption. Therefore, only monolayer adsorption occurred on its surface, in spite of any surface modification. According to Kadirvelu et al. (2001), the essential characteristics of Langmuir isotherm can be explained in terms of a dimensionless constant separation factor $\left(R_{L}\right)$, defined by:

$$
R_{L}=\frac{1}{1+K_{L} C_{o}}
$$

where $K_{L}$ is the Langmuir constant and $C_{o}$ is the initial concentration of metal ion. The value of $R_{L}$ indicated the type of Langmuir isotherm to be irreversible $\left(R_{L}=0\right)$, favourable $\left(0<R_{L}<1\right)$, linear $\left(R_{L}=1\right)$, or unfavourable $\left(R_{L}>1\right)$. Table 2 shows that $\mathrm{Cr}$ sorption of all types of adsorbent in this study is favourable.

Comparison of Langmuir and Freundlich isotherm constants obtained from other studies using other adsorbents shows that the values obtained in this study are comparable (Schmuhl et al. 2001). Using Langmuir isotherm, the equilibrium data yielded the ultimate adsorption capacity value for the chitosan coated AOPSC on per gram basis of chitosan as $154 \mathrm{mg} \mathrm{Cr} / \mathrm{g}$. This adsorption capacity for chromium is considerably higher compared to the values obtained with other adsorbents (50 to $120 \mathrm{mg} / \mathrm{g}$ ) (Schmuhl et al. 2001).

After the adsorbent was saturated the metal ions, it was regenerated with $0.1 \mathrm{M}$ sodium hydroxide. Maximum desorption occurred within 5 bed volumes, while complete desorption occurred within 10 bed volumes.

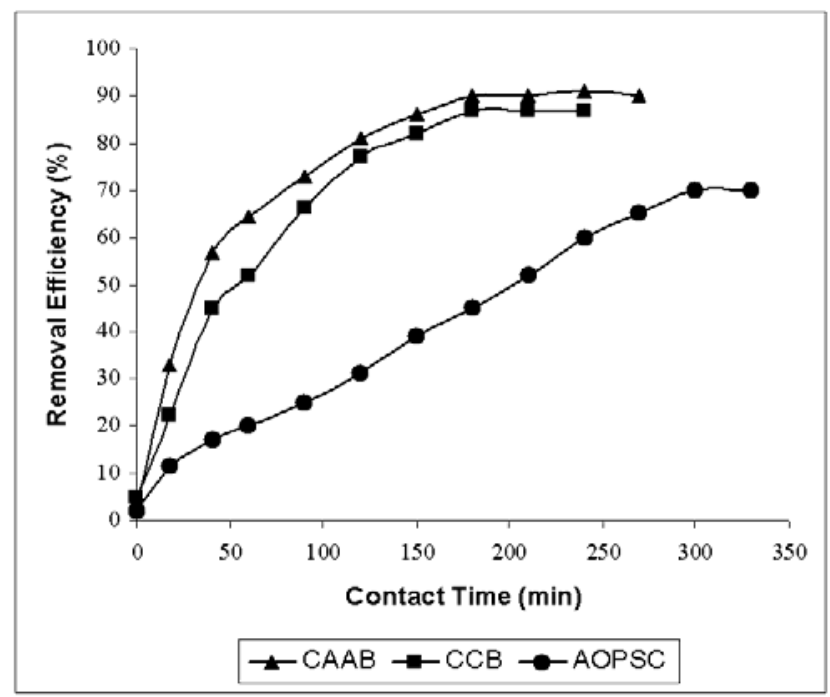

Figure 5. Effect of contact time on removal of chromium ions using different adsorbents.

$\mathrm{Cr}(\mathrm{VI})$ concentration was $20 \mathrm{mg} /$; $\mathrm{pH}$ of solution was 4;

Amount of each adsorbent: $40 \mathrm{~g} / \mathrm{l}$; Agitation speed: 200 rpm;

Temperature was maintained at $25^{\circ} \mathrm{C}$. 
In conclusion, it has been shown that the use chitosan coated acid treated oil palm shell charcoal for chromium ion removal appears to be technically feasible, eco-friendly and with high efficacy. Besides that, being composed entirely of agricultural and fishing industry waste, it helps in reduction of waste generation. The adsorbent can be regenerated by using sodium hydroxide, and therefore can be reused. This adsorbent can be a good candidate for adsorption of not only chromium ions but also other heavy metal ions in wastewater stream.

\section{REFERENCES}

AKSU, Z. Equilibrium and kinetic modeling of cadmium(II) biosorption by $C$. vulgaris in a batch system: effect of temperature. Separation and Purification Technology, 2001, vol. 21, p. 285-294.

BABEL, S. and KURNIAWAN, T.A. Cr (VI) removal from synthetic wastewater using coconut shell charcoal and commercial activated carbon modified with oxidizing agent and/or chitosan. Chemosphere, February 2004, vol. 54, no. 7, p. 951-967.

BAILEY, S.E.; OLIN, T.J.; BRICKA, R.M. and ADRIAN, D.D. A review of potentially low costs sorbents for heavy metals. Water Research, 1999, vol. 33, no. 11, p. 24692479.

BAILEY, S.E.; OLIN, T.J. and BRICKA, R.M. Low-Cost Sorbents: Literature Summary. Technical Report SERDP97-1, U.S. Army Engineer Waterways Experiment Station, Vicksburg, MS. 1997.

BENITO, Y. and RUIZ, M.L. Reverse osmosis applied to metal finishing wastewater. Desalination, 2002, vol. 142, no. 3, p. 229-234.

CADDICK, S. Microwave-assisted organic reactions. Tetrahedron, 1995, vol. 51, no. 38, p. 10403-10432.

CHAKRAVARTY, $\quad$ S.; $\quad$ DUREJA, $\quad$ V.; BHATTACHARYYA, G.; MAITY, S. and BHATTACHARJEE, S. Removal of arsenic from groundwater using low cost ferruginous manganese ore. Water Research, 2002; no. 36, vol. 3, p. 625-632.

CHAN, K.W. Biomass production in the oil palm industry. In: SINGH, G. et. al. eds. Oil palm and the environment: A Malaysian perspective. Malaysian Oil Palm Growers' Council, Kuala Lumpur, 1999, p. 41-53.

CHEN, J.P. and CHANG, K.C. Immobilization of chitinase on a reversibly soluble-insoluble polymer for chitin hydrolysis. Journal of Chemical Technology and Biotechnology, June 1994, vol. 60, no. 2, p. 133-140.
CLESCERI, L.S.; GREENBERG, A.E. and EATON, A.D. Standard methods for the examination of water and wastewater. $20^{\text {th }}$ ed. American Public Health Association, Washington, 1998; 1325 p. ISBN 0875532357.

COUGHLIN, R.W.; DESHAIES, M.R. and DAVIS, E.M. Preparation of chitosan for heavy metal removal. Environmental Progress, 1990, vol. 9, p. 35.

DAMBIES, L.; GUIMON, C.; YIACOUMI, S. and GUIBAL, E. Characterization of metal ion interactions with chitosan by X-ray photoelectron spectroscopy. Colloids and Surfaces, 2001, A., vol. 177, p. 203-214.

DEANS, J.R. and DIXON, B.G. Uptake of $\mathrm{Pb}^{2+}$ and $\mathrm{Cu}^{2+}$ by novel biopolymers. Water Research, 1992, vol. 26, no. 4, p. 469-472.

DESHPANDE, M.V. Enzymatic degradation of chitin and its biological applications. Journal of Scientific and Industrial Research, Sci. Ind. Res.,1986, vol. 45, p. 277281.

FARIA, P.C.C.; ORFAO, J.J.M. and PEREIRA, M.F.R. Adsorption of anionic and cationic dyes on activated carbons with different surface chemistries. Water Research, April 2004, vol. 38, no. 8, p. 2043-2052.

FU, M.; TANG, L.; ZHANG, P. and SHEN, D. Study on adsorption mechanism of $\mathrm{Cr}$ (VI) by CHT. Gongcheng Kexueban, (Journal of Sichuan Union University), 1997, vol. 1, 1997, p. 8-13.

GOTOH, T.; MATSUSHIMA, K and KIKUCHI, K.I. Preparation of alginate-chitosan hybrid gel beads and adsorption of divalent metal ions. Chemosphere, April 2004, vol. 55, no. 1, p. 135-140.

GUO, J. and LUA, A.C. Preparation and characterization of adsorbents from oil palm fruit solid waste. Journal of Oil Palm Research Malaysian Palm Oil Board, 2000, vol. 12, p. 64-70.

GUO, J. and LUA, A.C. Characterization of chars pyrolyzed from oil palm stones for preparation of activated carbons. Journal of Analytical and Applied Pyrolysis, 1998, vol. 46, no. 2, p. 113.

HUSSEIN, M.Z.; TARMIZI, R.S.H.; ZAINAL, Z.; IBRAHIM, R. and BADRI, R.M. Preparation and characterization of active carbons from oil palm shells. Carbon, 1996, vol. 34, no. 11, p. 1447-1453.

ILYINA, A.V.; TIKHONOV, V.E.; VARLAMOV, V.P.; RADIGINA, L.A.; TATARINOVA, N.Y. and YAMSKOV, I.A. Preparation of affinity sorbents and isolation of 
individual chitinases from a crude supernatant produced by Streptomyces kurssanovii by a one-step affinity chromatographic system. Biotechnology and Applied Biochemistry, April 1995, vol. 21, no. 2, p. 139-148.

KADIRVELU, K.; THAMARAISELVI, K. and NAMASIVAYAM, C. Adsorption of nickel (II) from aqueous solution onto activated carbon prepared from coirpith. Separation and Purification Technology, 2001, vol. 24, p. 497-505.

KHMELNITSKY, Y.L. and RICH, J.O. Biocatalysis in non aqueous solvents. Current Opinion in Chemical Biology, 1999, vol. 3, p. 47-53.

KORTENKAMP, A.; CASADEVALL, M.; FAUX, S.P.; JENNER, A.; SHAYER, R.O.J.; WOODBRIDGE, N. and O'BRIEN, P. A role for molecular oxygen in the formation of DNA damage during the reduction of the carcinogen chromium (VI) by glutathione, Archives of Biochemistry and Biophysics, 1996, vol. 329, no. 2, p. 199-208.

LEON Y LEON, C.A.; SOLAR, J.M.; CALEMMA, V. and RADOVIC, L.R. Evidence for the protonation of basal plane sites on carbon. Carbon, 1992, vol. 30, no. 5, p. 797811.

LYTLE, C.M.; LYTLE, F.W.; YANG, N.; QIAN, J.H.; HANSEN, D.; ZAYED, A. and TERRY, N. Reduction of $\mathrm{Cr}$ (VI) to Cr (III) by wetland plants: Potential for in situ heavy metal detoxification. Environmental Science and Technology, 1998, vol. 32, p. 3087-3093.

MENENDEZ, J.A.; PHILLIPS, J.; XIA, B. and RADOVIC, L.R. On the modification and characterization of chemical surface properties of activated carbon: in the search of carbons with stable basic properties. Langmuir, 1996, vol. 12, no. 18 , p. 4404-4410.

MODAK, J.M. and NATARAJAN, K.A. Biosorption of metals using nonliving biomass: A review. Mineral Metallurgical Process, 1995; vol. 12, no. 4, p. 189-196.

MONSER, L., and ADHOUM, N. Modified activated carbon for the removal of copper, zinc, chromium, and cyanide from wastewater. Separation and Purification Technology, 2002, vol. 26, no. 2-3, p. 137-146.

MOSTAFA, M.R. Adsorption of mercury, lead and cadmium ions on modified activated carbon. Adsorption Science and Technology, 1997, vol. 15, no. 8, p. 551-557.

NORMAH, M.; TEO, K.C. and WATKINSON, A.P. Preparation and characterization of activated carbon derived from oil palm shells using a fixed bed pyrolyser. In: HASHIM, M.A. ed. Bioproducts Processing: Technologies for the tropics. Institute of Chemical Engineers, Rugby, United Kingdom, 1995, p. 93. ISBN

OLIN, T.J.; ROSADO, J.M.; BAILEY, S.E. and BRICKA, R.M. Low cost sorbents screening and engineering analysis of zeolite for treatment of metals contaminated water and soil extracts - final report. Report SERDP, 1996; 96-387, prepared for USEPA and SERDP.

OUKI, S.K.; NEUFELD, R.D. and PERRY, R. Use of activated carbon for the recovery of chromium from industrial wastewaters. Journal of Chemical Technology and Biotechnology, 1997, vol. 70, no. 1, p. 3-8.

PARK, S. and JUNG, W.Y. Removal of chromium by activated carbon fibers plated with copper metal. Carbon Scence, 2001, vol. 2, no. 1, p. 15-21.

RADOVIC L.R.; SILVA, I.F.; UME, J.I.; MENENDEZ, J.A.; LEON Y LEON, C.A. and SCARONI, A.W. An experimental and theoretical study of the adsorption of aromatics possessing electron-withdrawing and electrondonating functional groups by chemically modified activated carbons. Carbon, 1997, vol. 35, no. 9, p. 13391348.

RAJI, C. and ANIRUDHAN, T.S. Chromium (VI) adsorption by sawdust: kinetics and equilibrium. Indian Journal of Chemical Technology, 1997, vol. 4, no. 5, p. 228-236.

RAMOS, R.L.; RANGEL-MENDEZ, J.R.; MENDOZABARRON, J.; FUENTES-RUBIO, L. and GUERREROCORONADO, R.M. Adsorption of cadmium (II) from aqueous solution onto activated carbon. Water Science Technology, 1997, vol. 30, p. 191-197.

RENGARAJ, S.; YEON, K.H. and MOON, S.H. Removal of chromium from water and wastewater by ion exchange resins. Journal of Hazardous Materials, October 2001, vol. 87, no. 1-3, p. 273-287.

RODRIGUEZ-REINOSO, F. The role of carbon materials in heterogeneous catalysis. Carbon, 1998, vol. 36, no. 3, p. 159-175.

ROY, I.; SARDAR, M. and GUPTA, M.N. Hydrolysis of chitin by PectinexTM. Enzyme and Microbial Technology, 2003, vol. 32, no. 5, p. 582-588.

SCHMUHL, R.; KRIEG, H.M. and KEIZER, K. Adsorption of $\mathrm{Cu}$ (II) and $\mathrm{Cr}$ (VI) ions by chitosan: Kinetics and equilibrium studies. Water S.A., 2001; vol. 27, no. 1, p. 1-8.

SHIM, J.W.; PARK, S.J. and RYU, S.K. Effect of modification with $\mathrm{HNO}_{3}$ and $\mathrm{NaOH}$ by pitch-based activated carbon fibers. Carbon, 2001; vol. 39, no. 11, p. 
1635-1642.

SRIDAR, V. Microwave radiation as a catalyst for chemical reactions. Current Science, 1998, vol. 74, no. 5, p. 446-450.

TAN, W.T.; OOI, S.T. and LEE, C.K. Removal of chromium (VI) from solution by coconut husk and palm pressed fibers. Environmental Technology, March 1993, vol. 14, no. 3, p. 277-282.

TIEMANN, K.J.; GARDEA-TORRESDEY, J.L.; GAMEZ, G.; DOKKEN, K and SIAS, S. Use of X-ray absorption and esterification to investigate $\mathrm{Cr}$ (III) and Ni (II) ligands in Alfafa biomass. Environmental Science and Technology, 1999, vol. 33, no. 1, p. 150-155.

TOLES, C.A.; MARSHALL, W.E. and JOHNS, M.M. Surface functional groups on acid activated nutshell carbons. Carbon, January 1999, vol. 37, no. 8, p. 12071214.

UDAYBHASKAR, P.; IYENGAR, L. and PRABHAKARA, R.A.V.S. Hexavalent chromium interaction with chitosan. Journal of Applied Polymer Science, February 1990, vol. 39, no. 3, p. 739-747.

VEGLIO, F. and BEOLCHINI, F. Removal of heavy metals by biosorption: A review. Hydrometallurgy, 1997, vol. 44, no. 3, p. 301-316.

WITTBRODT, P.R. and PALMER, C.D. Effect of temperature, ionic strength, background electrolytes and $\mathrm{Fe}$ (III) on the reduction of hexavalent chromium by soil humic substances. Environmental Science and Technology, 1996, vol. 30, no. 8, p. 2470-2477.

YANG, T.C. and ZALL, R.R. Adsorption of metals by natural polymers generated from sea food processing wastes. Industrial and Engeneering Chemistry Produc Research and Developmet, 1984, vol. 23, p. 168-172.

YURLOVA, L.; KRYVORUCHKO, A. and KORNILOVICH, B. Removal of Ni (II) ions from wastewater by micellar-enhanced ultrafiltration. Desalination, 2002, vol. 144, no. 255-260. 